\title{
Multi-parameter crack tip stress state description for estimation of fracture process zone extent in silicate composite WST specimens
}

\author{
Václav Veselý, Jakub Sobek, Lucie Šestáková, Petr Frantík \\ Brno University of Technology, Faculty of Civil Engineering, Institute of Structural Mechanics, Brno, Czech Republic \\ Stanislav Seitl \\ Academy of Sciences of the Czech Republic, v. v. i., Institute of Physics of Materials, Brno, Czech Republic
}

\begin{abstract}
For wedge splitting test specimens, the stress and displacement fields both in the vicinity and also in larger distance from the crack tip are investigated by means of numerical methods. Several variants of boundary conditions were modeled. The stress intensity factor $K, T$-stress and even higher-order terms of William series were determined and subsequently utilized for analytical approximation of the stress field. A good fit between the analytical and numerical solution in dependence on the distance from the crack tip was shown, compared and discussed. Presented approach is considered as suitable for estimation of the fracture process zone extent in silicate composite materials.
\end{abstract}

KEYWORDS. Near-crack tip fields; Williams series; Higher-order terms; Stress field approximation; Wedge splitting test; Fracture process zone.

\section{INTRODUCTION}

7 he research of the author's collective is focused on estimation of the size, shape and other relevant properties of the zone with nonlinear material behaviour evolving at the tip of a propagating crack in composite materials with disordered internal structure, particularly those with quasi-brittle nature which exhibit strain softening. Characteristics of the zone, in the case of the materials in question referred to as the fracture process zone (FPZ), are intended to be utilized within methods for evaluation of fracture mechanical parameters in order to diminish the effects of the test specimen's size, geometry and free boundaries on their values, mainly the fracture energy, determined from records of tests on laboratory-sized specimens. This topic is intensively researched in last decades [1-6].

A determination procedure taking into account the mentioned effects is currently under development by the authors $[7,8]$ and outputs of individual parts of the procedure are being tested, verified and validated at present, both from the perspective of the FPZ extent estimation [9-11] and also the crack tip stress state description [12-14]. This paper is particularly focused on investigation of differences in crack tip stress state caused by changes in the test geometry (the specimen's shape and boundary conditions) resulting in differences in the shape and size of the FPZ. Variants of what is referred to as the wedge splitting test (WST) geometry are taking into account for this study.

A precise description of the stress state in the cracked body is necessary for the procedure of the FPZ extent estimation. For that purpose, multi-parameter fracture mechanics is employed as the size proportions of the FPZ in relation to the whole specimen is much larger in the case of the studied quasi-brittle composites than that of e.g. plastic zone in metals. Therefore, the FPZ extent analysis is preceded by a detailed finite element method (FEM) analysis of the stress and displacement fields in the test specimens serving as input to the over-deterministic method [15] for evaluation of higherorder terms of the Williams power series [16] via which the fields are approximated. Main attention is given to this issue in 
the paper; the accuracy of the approximation is investigated. Some examples of results of the verification analyses are presented in conclusion.

\section{MULTI-PARAMETER DESCRIPTION OF THE STRESS AND DISPLACEMENT FIELDS IN A CRACKED BODY}

Multi-parameter fracture mechanics [17-19] is based on the analytical description of the stress and deformation fields in the body with crack by means of Williams expansion [16]. This infinite power series for a homogeneous elastic isotropic body can be expressed for the stress tensor $\{\sigma\}$ and deformation vector $\{u\}$ as

$$
\begin{aligned}
& \left\{\begin{array}{l}
\sigma_{x} \\
\sigma_{y} \\
\tau_{x y}
\end{array}\right\}=\sum_{n=1}^{\infty} \frac{n}{2} r^{\frac{n}{2}-1} A_{n} \cdot\left\{\begin{array}{l}
{\left[2+(-1)^{n}+\frac{n}{2}\right] \cos \left(\frac{n}{2}-1\right) \theta-\left(\frac{n}{2}-1\right) \cos \left(\frac{n}{2}-3\right) \theta} \\
{\left[2-(-1)^{n}-\frac{n}{2}\right] \cos \left(\frac{n}{2}-1\right) \theta+\left(\frac{n}{2}-1\right) \cos \left(\frac{n}{2}-3\right) \theta} \\
-\left[(-1)^{n}+\frac{n}{2}\right] \sin \left(\frac{n}{2}-1\right) \theta+\left(\frac{n}{2}-1\right) \sin \left(\frac{n}{2}-3\right) \theta
\end{array}\right\} \\
& \left\{\begin{array}{l}
u \\
v
\end{array}\right\}=\sum_{n=1}^{\infty} \frac{r^{n / 2}}{2 \mu} A_{n} \cdot\left\{\begin{array}{l}
\left(\kappa+\frac{n}{2}+(-1)^{n}\right) \cos \frac{n}{2} \theta-\frac{n}{2} \cos \left(\frac{n}{2}-2\right) \theta \\
\left(\kappa-\frac{n}{2}-(-1)^{n}\right) \sin \frac{n}{2} \theta+\frac{n}{2} \sin \left(\frac{n}{2}-2\right) \theta
\end{array}\right.
\end{aligned}
$$

respectively, where $r$ and $\theta$ are polar coordinates centered at the crack tip (considering the direction of the crack propagation in positive $x$-axis), $\mu$ is a shear modulus, $E$ and $v$ are Young's modulus and Poisson's ratio; $n$ represents index of term of the power expansion and $\kappa$ is Kolosov's constant (depends on plane stress or plane strain state). Coefficients $A_{n}$ are functions of relative crack length $\alpha$. They can be with convenience expressed as dimensionless functions (with regard to the loading) in various ways. We alternatively employ the two most frequently used ones in this paper which are adopted from $[20,21]$ and $[22,23]$, and they are expressed here only for the parameters presented later in the paper. With respect to the mentioned references they can be written as

$$
B_{1}(\alpha)=\frac{A_{1}(\alpha) \sqrt{2 \pi}}{K_{0}}=\frac{K_{\mathrm{I}}(\alpha)}{K_{0}} \quad \text { and } \quad B_{2}(\alpha)=\frac{4 A_{2}(\alpha) \sqrt{\pi a}}{K_{\mathrm{I}}(\alpha)}=\frac{T(\alpha) \sqrt{\pi a}}{K_{\mathrm{I}}(\alpha)}
$$

and

$$
g_{n}(\alpha)=\frac{A_{n}(\alpha)}{\sigma} W^{\frac{n-2}{2}} \quad \text { for } \quad n=1,3,4 \ldots, N \quad \text { and } \quad g_{2}=t(\alpha)=\frac{4 A_{2}(\alpha)}{\sigma}
$$

respectively. In these formulas, $\sigma$ is nominal stress in the central plane of the specimen caused by (usually only the splitting component $P_{\mathrm{sp}}$ of) the applied load (i.e. $\sigma=P_{\mathrm{sp}} / B W$ ), $K_{0}$ is the normalized stress intensity factor (i.e. $\left.K_{0}=P_{\text {sp }} / B \sqrt{W}\right), K_{\mathrm{I}}$ is the stress intensity factor, $T$ is $T$-stress, $a$ is the crack length, $W$ and $B$ is the specimen's width and breadth, respectively.

The crack length $a$ is defined as a distance from the point of the splitting force application to the crack tip, i.e. $a=c+d_{\mathrm{n}}-h$ in the case of the WST, see Fig. 3. Consequently, the relative crack length $\alpha$ is defined as the ratio of the crack length $a$ and the effective specimen width

$$
\alpha=\frac{a}{W_{\mathrm{ef}}}=\frac{c+\left(d_{\mathrm{n}}-b\right)}{W-b}
$$


Coefficients of the terms of the Williams power expansion used/presented in this paper were determined using direct methods which evaluate results gained via FEM computations.

Values of first two terms ( $K$ and $T$-stress) were computed both using the direct method (e.g. [24]) or determined with help of quarter-point crack-tip elements (e.g. [25]). For the latter case, following formulas are used to calculate $K$ and $T$

$$
K_{\mathrm{I}}=\frac{E}{3(1+v)(1+\kappa)} \sqrt{\frac{2 \pi}{l}}\left[4 v_{i}^{(\mathrm{B})}-\frac{v_{i}^{(\mathrm{C})}}{2}\right], \quad T=-\frac{2 E}{\left(1-v^{2}\right) l}\left[u_{i}^{(\mathrm{A})}-4 u_{i}^{(\mathrm{B})}+2 u_{i}^{(\mathrm{C})}\right]
$$

where $l$ is the element length, $u$ and $v$ are displacement components in the $x$ and $y$ directions, respectively. The (A), (B), and (C) superscripts indicate the FE node positions as follows: A - node at the crack tip, B - node at a distance of $1 / 4 l$ from the crack tip, and C - node at a distance of $l$. For the direct method [24] the estimation of the fracture parameters is derived directly from the stress description via eq. (1) (for max. $n=2$ ). Let us note that several alternatives to the methods used in this paper are available in literature, especially for the determination of $K$ (e.g. [26]).

Coefficients of even the higher-order terms of the power expansion were calculated (alternatively to the previouslymentioned techniques for the first two ones, however, as the only used technique for the other ones) by using the overdeterministic method (ODM) [15]. ODM, based on the linear least-squares formulation, provides solution of the system of $2 k$ equations (resulting from eq. (2)), where $k$ represents the number of selected nodes around the crack tip, leading to values of $N$ selected terms of the series. They can be calculated from the knowledge of the values of components $u, v$ of the displacement vector and coordinates $r, \theta$ of the selected nodes. Similarly to the above-mentioned techniques, inputs to the ODM were also obtained by FEM computations.

Motivation of the determination of the higher-order of terms of the power series dwells in the requirements on the estimation of the crack-tip nonlinear zone extent. They must be taken into account in order to describe the fields in more distant surroundings of the crack tip, especially in the case of the quasi-brittle materials.

\section{WEDGE SPLITTING TEST GEOMETRY - DEFINITION OF NUMERICAL STUDY}

$\mathrm{W}$

edge splitting test is a convenient and popular configuration for estimation of fracture parameters of silicatebased composites, mainly building materials. It has been introduced in 80ies of the last century [27,28]. For its advantages it is often used as an alternative of standard three-point bending test of notched beams. The test can be performed on specimens of various shapes, however also the test setup, i.e. the boundary conditions, can significantly differ. And that is true both for the boundary conditions related to the load application (see Fig. 1) and the specimen supports (see Figs. 2 and 3).

The differences in the load application and supporting are usually neglected, even fracture analyses utilizing functions of geometry corresponding to the compact tension test configuration are commonly published [29,30]. And if the $K$ calibration curves are computed for the WST geometry and presented in the literature (e.g. [31]), details of supports and load application are not properly taken into account. Particularly, the compressive component of the loading force $\left(P_{\mathrm{v}}\right.$ in Figs. 2 and 3) is ignored and only one central support is considered (except to [32], with regard to both aspects). Karihaloo and co-workers published the stress and displacement field description using as many as five terms of the Williams series $[22,23]$. Two variants of supports were modeled, but the compressive component of the applied loading was not considered too.

It is worth noticing that if a certain fracture analysis has to be conducted for which the stress/displacement fields in only the very vicinity of the crack tip is required (i.e. the case of brittle fracture with description of the fields via $K$ only), the simplifications mentioned in previous paragraph are possible (to some extent, i.e. when $T$-stress value is not too low or high).

In our work, three variants of supports (one central support, and two supports positioned $1 / 4 \mathrm{~W}$ and $1 / 8 \mathrm{~W}$ from the central plane, see Figs. 2 and 3) and two alternatives of load imposition (via loading platens with bearings placed inside the specimen's groove - platens I - and platens with bearings axes outside the groove - platens II, see Figs. 1, 3 left and right, respectively) are considered.

The influence of the boundary conditions of the WST test was analyzed in several relevant aspects in detail in previous works by the authors [32-34, 12-14] and results were compared with the crack-tip fields descriptions published in literature. Selected parts of the rather thorough study are presented in this paper. The study was first conducted in the 
framework of two-parameter fracture mechanics (investigation of the stress intensity factor $K$ and the $T$-stress, or their normalized values $B_{1}$ and $B_{2}$, respectively). Later, more terms of the Williams series was considered and coefficients of the first several ones (up to around 10) were determined, again either in their absolute values $A_{n}$ or expressed as the normalized shape functions $g_{n}$.

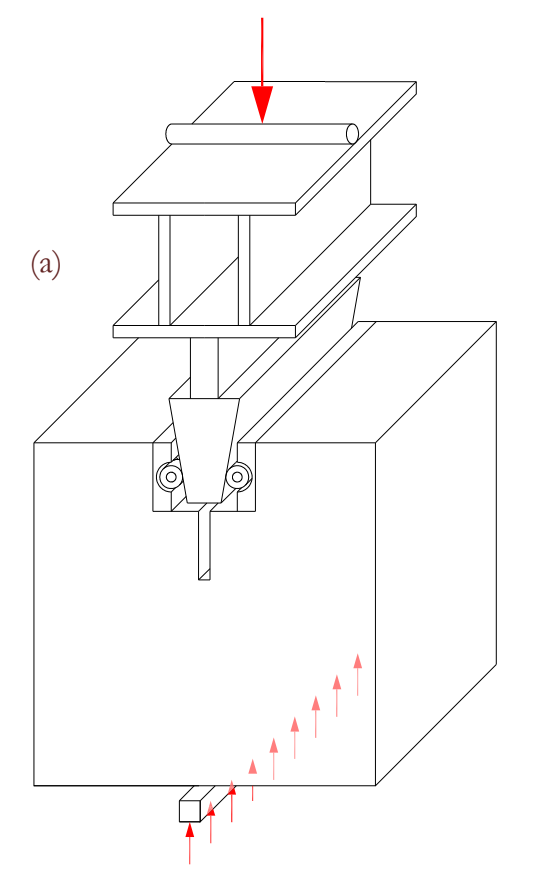

(b)

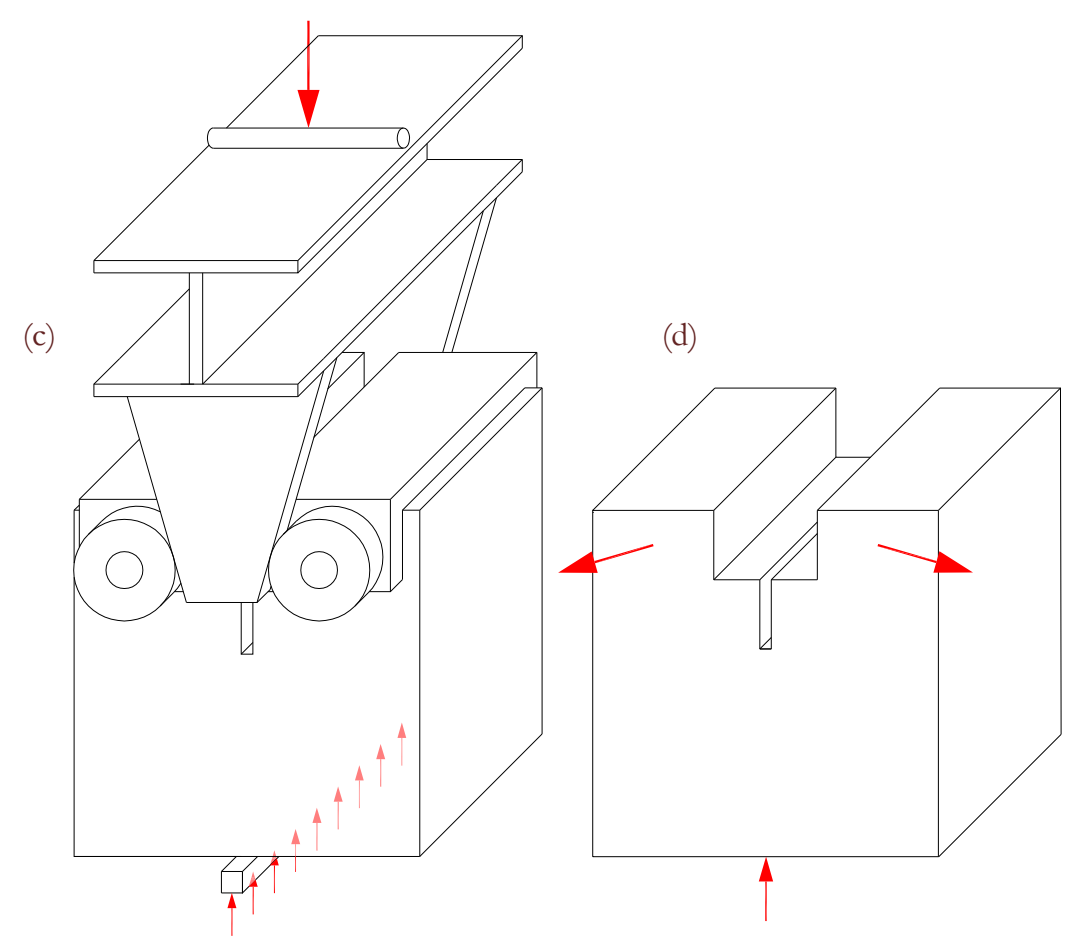

Figure 1: Variants of boundary conditions of the WST geometry in the area of the load application (compare (a), (b) vs. (c), (d)). 


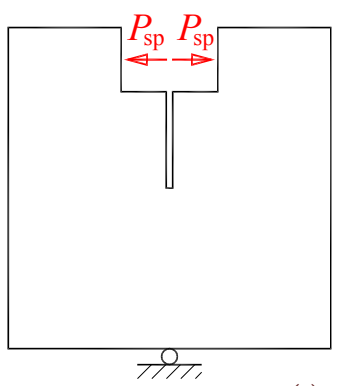

(a)

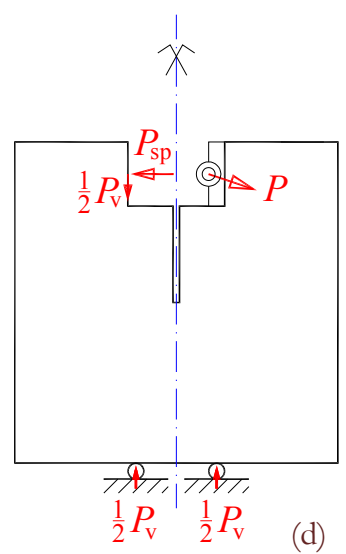

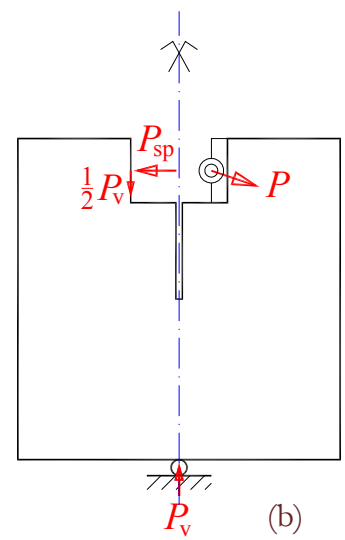
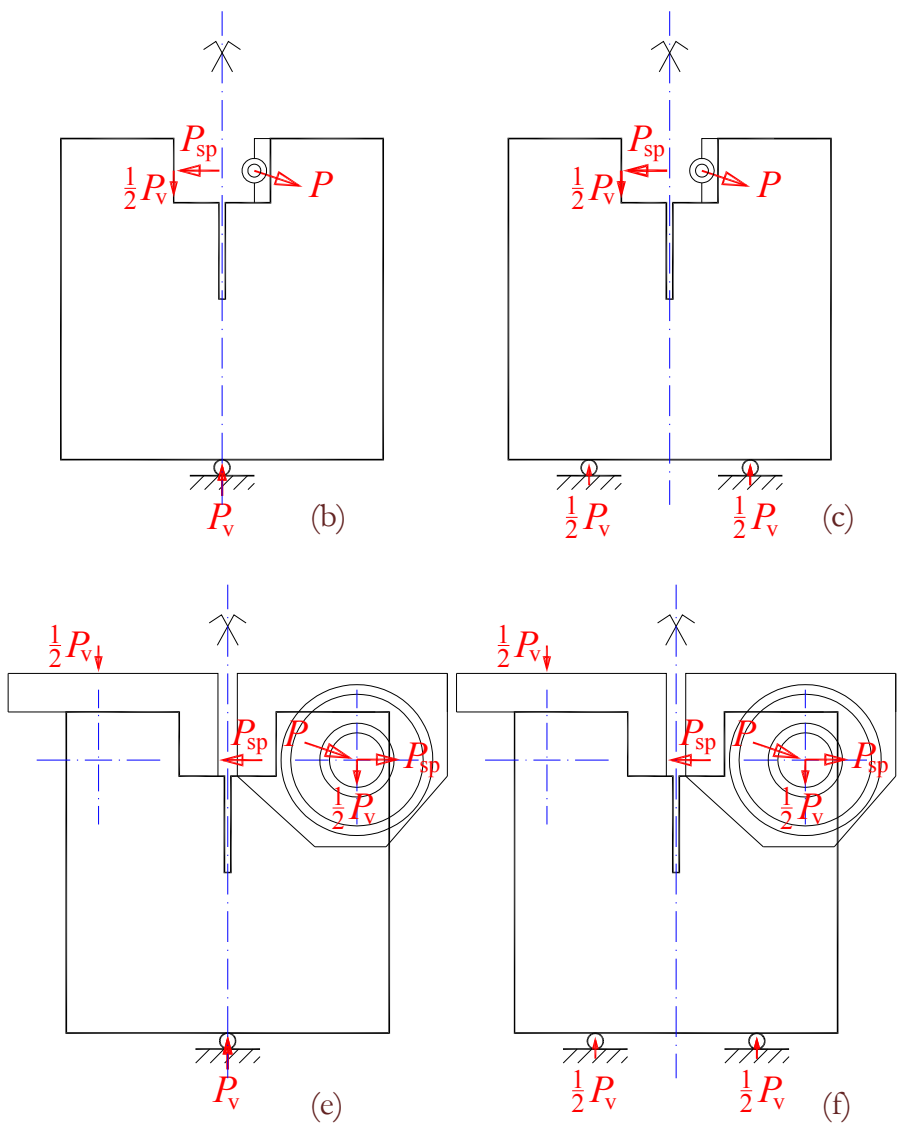

(e)

Figure 2: Schemes of variants of boundary conditions of the WST geometry in both the area of the load application (differences between (a) vs. (b), (c) and (d) vs. (e) and (f)) and supports (differences between (a) vs. (b) and (e) vs. (d) vs. (c) and (f)). Taking into account the vertical component of the loading force is essential.

\section{NUMERICAL MODELING}

he test configuration in considered variants of boundary conditions and specimen dimensions corresponding to results showed below are indicated in Fig. 3 and their values are summarized in Tab. 1.

\begin{tabular}{cc}
\hline \multicolumn{2}{c}{ Dimensions $[\mathrm{mm}]$} \\
$W$ & 100 \\
$B$ & 100 \\
$a$ & $20 \sim 80$ \\
$d_{\mathrm{n}}$ & 20 \\
$e$ & 35 \\
$f$ & 30 \\
$h$ & 15 \\
$i$ & 25 \\
\hline
\end{tabular}

Table 1: Individual dimensions of the modeled WST specimen. 


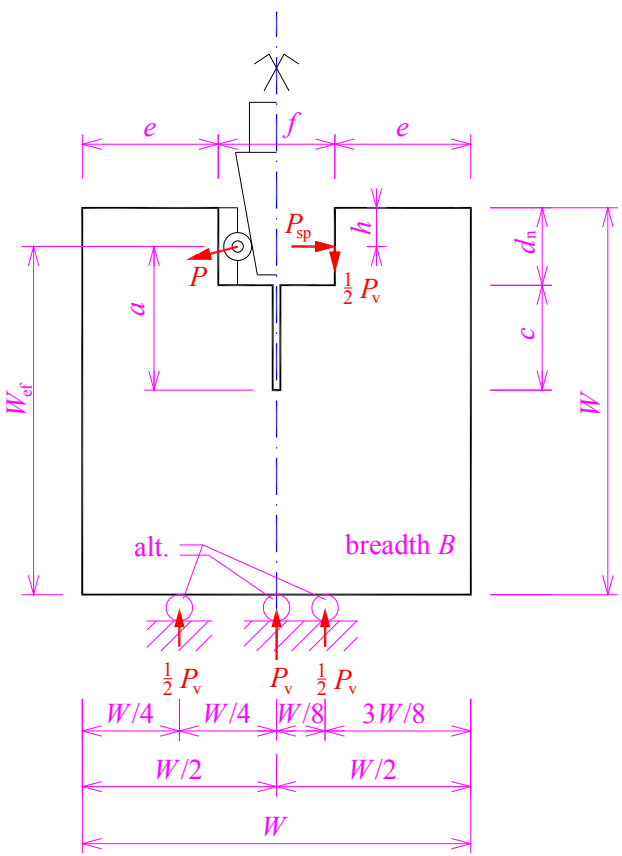

(a)

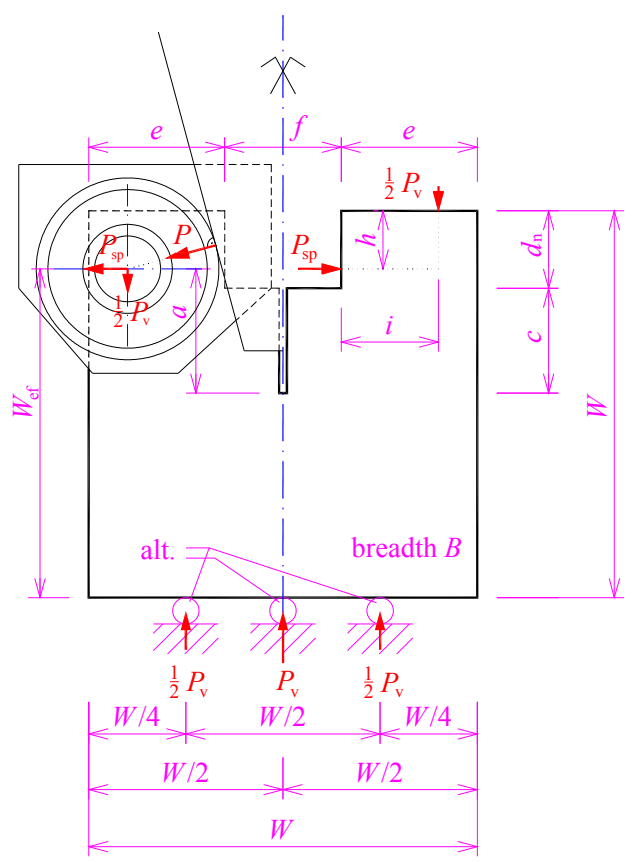

(b)

Figure 3: Sketch of the modeled WST specimen with considered variants of boundary conditions.

The numerical study was conducted in the ANSYS FEM software [35]. All simulations were modeled in 2D under plane strain condition. The FE mesh was generated from 8-nodes isoparametric elements. Linear elastic isotropic material of the cementitious composite specimen and the steel loading platens was defined by Young's moduli $E=40$ and $210 \mathrm{GPa}$ and Poisson's ratios $v=0.2$ and 0.3 , respectively. Fig. $4 \mathrm{a}$ and b shows a static scheme and FE model for a variant of the WST with platens II and one central support (a half of the specimen with symmetry conditions). A detail of the near-crack-tip FE mesh is depicted in Fig. $4 \mathrm{c}$ and d. Fig. $4 \mathrm{~d}$ shows utilization of the quarter-point singular elements at the very crack tip (used for calculation of $K$ and $T$, or $B_{1}$ and $B_{2}$, via the first two mentioned methods), in Fig. 4c the (near-crack-tip) ring of nodes is indicated from which coordinates and computed displacements are used as inputs into the ODM for determination shape functions $g_{n}$.

\section{RESULTS AND DISCUSSION, APPLICATION OF THE MULTI-PARAMETER FRACTURE MECHANICS}

his section presents some of the results obtained within the conducted study. In agreement with the definition of the normalized dimensionless expressions of the coefficients of the Williams series' terms mentioned above, the influence of boundary conditions on the stress and displacement fields' description is indicated in graphs in Figs. 5

and 6 .

Fig. 5 shows the parameters $B_{1}$ and $B_{2}$ as functions of the relative crack length $\alpha$. Differences in the boundary conditions are apparently distinguishable for the latter one, particularly they are evident for short cracks (up to approx. $a<0.4$, which corresponds to the influence of the loading platens, see differences between the "platens I" and "platens II" cases) as well as long cracks (i.e. from approx. $a>0.4$, influence of the number and mutual distance of supports). It is also clearly seen, and that is true for almost the whole studied range of $\alpha$, that the neglecting of the compressive force $P_{\mathrm{v}}$ produces larger error if a single support is used. Effect of boundary conditions on the first term of the series is rather low, as can be expected, since the singular term domain is the very vicinity of the crack tip only.

The graphs in Fig. 6 show shape functions corresponding to two selected higher-order terms coefficients, $g_{4}$ and $g_{7}$, and only the effect of supports can be investigated. Both curves are from simulations with loading platens II, therefore no differences between the curves are obvious up to a fracture process stage when the crack tip approaches the back-face of the WST specimen (see the magnified sections of the graphs in Fig. 6b and $\mathrm{d}$ ). Differences are apparent only for the relative crack lengths around 0.9 and larger provided that compressive component of the loading force $P_{\mathrm{v}}$ is considered. If 
$P_{\mathrm{v}}$ is neglected, significant difference appears earlier, around $\alpha=0.75$ (see Fig. 6a and b, where comparison with [23], which ignores $P_{\mathrm{v}}$, is shown).

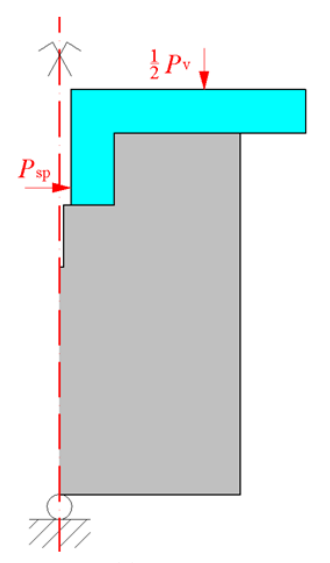

(a)

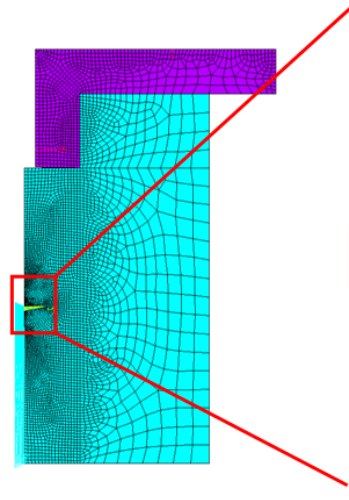

(b)

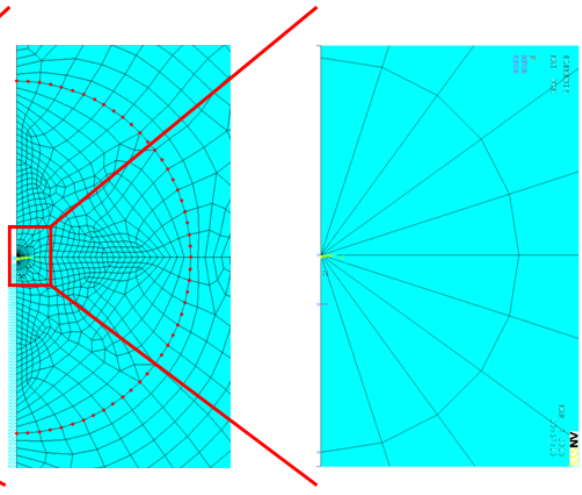

(d)

Figure 4: 2D representation of the WST - static scheme with indication of boundary conditions (a) and corresponding FE model (b). Example of the FE mesh around the crack tip: ring of selected nodes (at radius $5 \mathrm{~mm}$ from the crack tip) (c) and quarter-point cracktip elements (d).

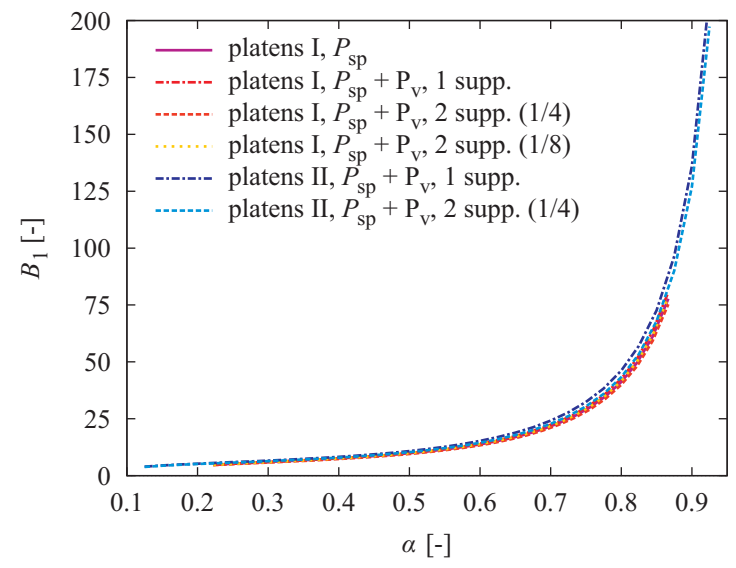

(a)

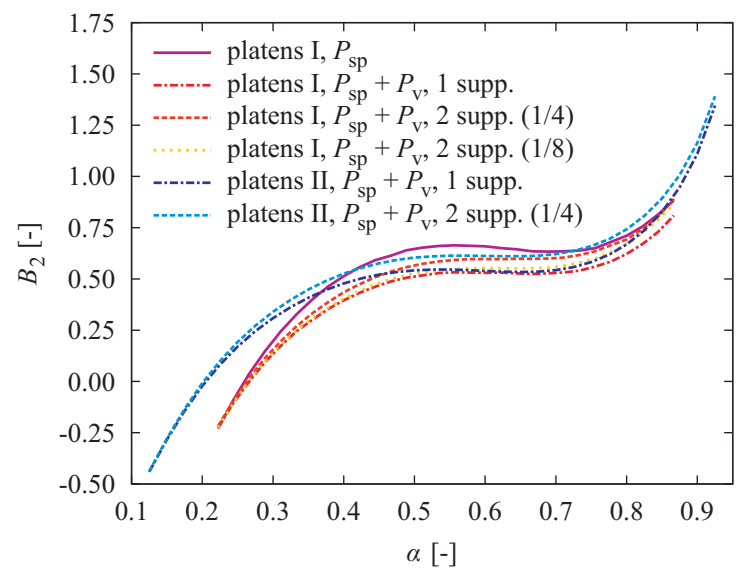

(b)

Figure 5: Geometry factors $B_{1}$ and $B_{2}$ as functions of the relative crack length $\alpha$ for various considered boundary conditions.
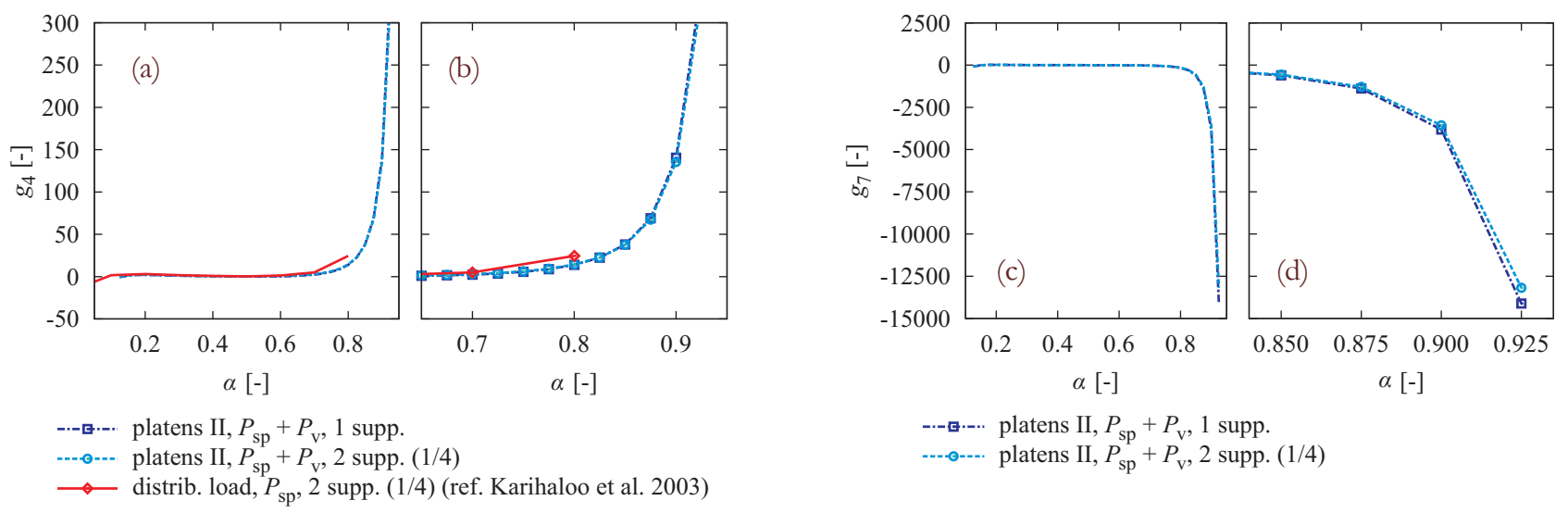

Figure 6: Shape functions $g_{4}$ and $g_{7}$ as functions of the relative crack length $\alpha$ for two support variants.

An accurate knowledge of the mechanical fields in the cracked body is necessary for a relevant fracture analysis. As an example, a reconstruction of the stress fields in the WST (platens II, one support, $P_{\mathrm{v}}$ considered) is introduced. Fig. 7 
displays distributions of selected stress components (in this case e.g. $\sigma_{x}, \sigma_{1}$ ) over the specimen (symmetrical half) taking into account various ranges of terms of the Williams series (whose coefficients were determined via methods mentioned above). The fields correspond to load $P_{\mathrm{sp}}=1 \mathrm{kN}$. Different relative crack lengths were chosen for each case. It is clearly visible that if the knowledge of the stress field is requested even in larger distance of the crack tip, the approximation of the field by higher number of terms of the series is essential. The isolines in the second row of Fig. 7 may represent a nonlinear (plastic) zone extent provided that Rankine failure criterion was applied. If the strength limit of the material were 2 ( 1 and 0.5$) \mathrm{MPa}, 4$ (around 7 and more than 12, respectively) terms would be necessary for the accurate enough description of the nonlinear zone.

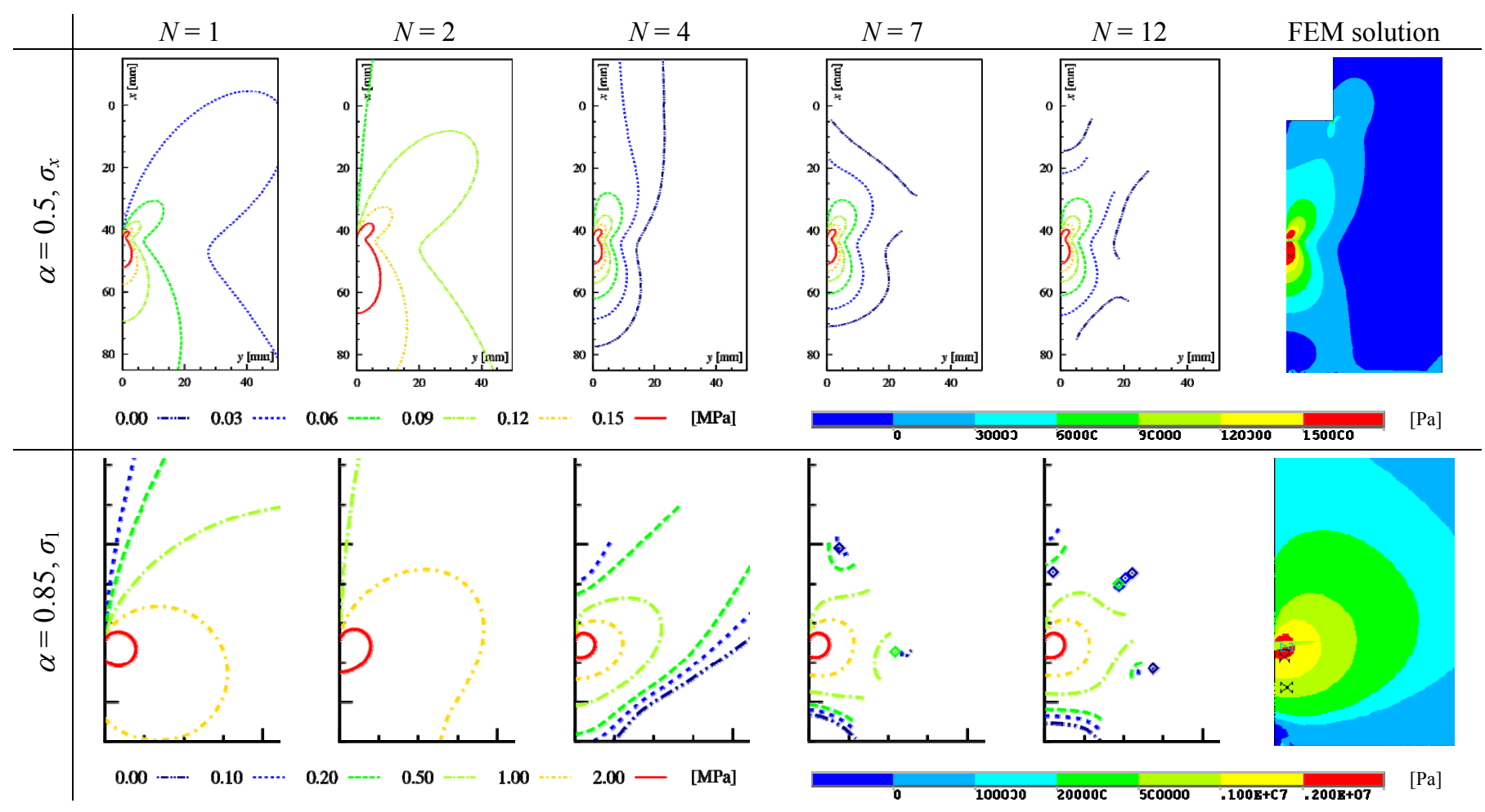

Figure 7: Comparison of stress fields $\left(\sigma_{x}, \sigma_{1}\right)$ in WST specimen reconstructed by means of Williams power expansion using various ranges of terms of the series (from left $1,2,4,7$, and 12 , respectively) with the numerical solution (right). The crack tip region is magnified in the second row (the axes scale is kept the same as in the first row).

\section{CONCLUSIONS}

A nalysis of the stress and displacement fields near a crack tip in a WST specimen is presented. For this purpose, multi-parameter fracture mechanics was applied. Influence of the boundary conditions on the stress intensity factor and the $T$-stress (representing the first two terms of Williams expansion) was investigated and several resulting conclusions discussed. Moreover, even the higher-order terms of the series (up to order of 12) were calculated by means of the over-deterministic method. Subsequently, various ranges of them were used for reconstruction of the stress field around the crack tip and compared with stress distribution obtained by means of FEM. The results clearly show that especially for long cracks and/or in larger distances from the crack tip the accurate approximation of the stress field requires using more terms of the Williams expansion than it is usual within classical fracture mechanical approaches.

\section{ACKNOWLEDGEMENTS}

7 he work has been supported by the Czech Science Foundation, the project No. 104/11/0833, and Brno University of Technology, Specific Research program, project No. FAST-S-12-21/1653. 


\section{REFERENCES}

[1] Bažant, Z.P., Analysis of work-of-fracture method for measuring fracture energy of concrete, J. Engng. Mech. (ASCE), 122(2) (1996) 138-144.

[2] $\mathrm{Hu}, \mathrm{X} .-\mathrm{Z}$., Wittmann, F.H., Size effect on toughness induced by crack close to free surface, Engng. Fract. Mech., 65 (2000) 209-221.

[3] Duan, K., Hu, X.-Z., Wittmann, F.H., Boundary effect on concrete fracture and non-constant fracture energy distribution, Engng. Fract. Mech., 70 (2003) 2257-2268.

[4] Duan, K., Hu, X.-Z., Wittmann, F.H., Size effect on specific fracture energy of concrete, Engng. Fract. Mech., 74 (2007) 87-96.

[5] Hu, X.-Z., Duan, K., Size effect: Influence of proximity of fracture process zone to specimen boundary, Engng. Fract. Mech., 74 (2007) 1093-1100.

[6] Trunk, B., Wittmann, F. H., Influence of size on fracture energy of concrete, Mater. Struct., 34 (2001) 260-265.

[7] Veselý, V., Frantík, P., Keršner, Z., Cracked volume specified work of fracture, in: B.H.V. Topping, L.F. Costa Neves, R.C. Barros (Eds.), Proc. of $12^{\text {th }}$ Int. Conf. on Civil, Structural and Environmental Engineering Computing, Funchal, Portugal, Civil-Comp Press, Stirlingshire, UK, (2009) n.194. doi:10.4203/ccp.91.194.

[8] Veselý, V., Frantík, P., An application for the fracture characterization of quasi-brittle materials taking into account fracture process zone influence, submitted to Adv. Eng. Softw. (expected in 2013).

[9] Veselý, V., Frantík, P., Reconstruction of a fracture process zone during tensile failure of quasi-brittle materials, Appl. Comp. Mech., 4 (2010) 237-250.

[10] Veselý, V., Keršner, Z., Němeček, J., Frantík, P., Řoutil, L., Kucharczyková, B., Estimation of fracture process zone extent in cementitious composites, Chem. listy, 104 (2010) s382-s385,

[11] Frantík, P., Veselý, V., Keršner, Z., Parallelization of lattice modelling for estimation of fracture process zone extent in cementitious composites. Adv. Eng. Softw. (2013), http://dx.doi.org/10.1016/j.advengsoft.2012.11.020.

[12] Veselý, V., Šestáková, L., Seitl, S., Influence of boundary conditions on higher order terms of near-crack-tip stress field in a WST specimen, Key Eng. Mat., 488-489 (2012) 399-402.

[13] Veselý, V., Sobek, J., Šestáková, L., Seitl, S., Accurate description of near-crack-tip fields for the estimation of inelastic zone extent in quasi-brittle materials, Key Eng. Mat., 525-526 (2013) 529-532.

[14] Šestáková, L., Veselý, V., Sobek, J., Frantík, P., Accuracy of approximation of stress field in cracked bodies for failure zone extent estimation. Accepted to conference FraMCoS-8, Toledo, Spain, 10-14 March 2013.

[15] Ayatollahi, M.R, Nejati, M., An over-deterministic method for calculation of coefficients of crack tip asymptotic field from finite element analysis, Fatigue Fract. Engng. Mater. Struct., 34 (2010) 159-176.

[16] Williams, M.L., On the stress distribution at the base of a stationary crack, J. Appl. Mech. (ASME), 24 (1957) 109114.

[17] Berto, F., Lazzarin, P., Christopher, C.J., James, M.N., Characterization of crack tip stress fields, Forni di Sopra (UD), Italy, March 7-9, (2011) 88-95.

[18] Guagliano, M., Sangirardi, M., Sciuccati, A., Zakeri, M., Multiparameter analysis of the stress field around a crack tip, Procedia Engineering, 10 (2011) 2931-2936.

[19] Berto, F., Lazzarin, P., Multiparametric full-field representations of the in-plane stress fields ahead of cracked components under mixed mode loading, Int. J. Fatigue, 46 (2013) 16-26.

[20] Leevers, P.S., Radon, J.C., Inherent stress biaxiality in various fracture specimen geometries, Int. J. Fract., 19 (1983) 311-325.

[21] Knésl, Z., Bednár, K., Two-parameter fracture mechanics: determination of parameters and their values (in Czech), IPM AS CR, v. v. i., Brno, (1998).

[22] Karihaloo, B.L., Xiao, Q.Z., Higher order terms of the crack tip asymptotic field for a wedge-splitting specimen Int. J. Fract., 112 (2001) 129-137.

[23] Karihaloo, B.L., Abdalla, H., Xiao, Q.Z., Coefficients of the crack tip asymptotic field for wedge splitting specimen, Engng. Fract. Mech., 70 (2003) 2407-2420.

[24] Yang, B., Ravi-Chandar, K., Evaluation of elastic T-stress by the stress difference method, Engng. Fract. Mech., 64 (1999) 589-605.

[25] Tan, C.L., Wang, X., The use of quarter-point crack-tip elements for T-stress determination in boundary element method analysis, Engng. Fract. Mech., 70 (2003) 2247-2252. 
[26] Yang, Z. J., Chen, J. F., Holt, G. D., Efficient evaluation of stress intensity factors using virtual crack extension technique, Comp. Struct., 79(31) (2001) 2705-2715.

[27] Linsbauer, H.N., Tschegg, E.K., Fracture energy determination of concrete with cube-shaped specimens, Zement und Beton, 31 (1986) 38-40.

[28] Brühwiler, E., Wittmann, F.H., The wedge splitting test, a new method of performing stable fracture mechanics test, Engng. Fract. Mech., 35 (1990) 117-125.

[29] Reinhardt, H.W., Xu, S., Crack extension resistance based on the cohesive force in concrete, Engng. Fract. Mech., 64 (1999) 563-587.

[30] Xu, S., Reinhardt, H.W., Determination of double-K criterion for crack propagation in quasi-brittle fracture, Part III: Compact tension specimens and wedge splitting specimens, Int. J. Fract., 98 (1999) 179-193.

[31] Guinea, G.V., Elices, M., Planas, J., Stress intensity factors for wedge-splitting geometry, Int. J. Fract., 81 (1996) 113124.

[32] Seitl, S., Veselý, V., Řoutil, L., Two-parameter fracture mechanical analysis of a near-crack-tip stress field in wedge splitting test specimens, Comp. Struct., 89 (2011) 1852-1858.

[33] Seitl, S., Dymáček, P., Klusák, J., Řoutil, L., Veselý, V., Two-parameter fracture analysis of wedge splitting test specimen, in: B.H.V. Topping, L.F. Costa Neves, R.C. Barros (Eds.), Proc. of $12^{\text {th }}$ Int. Conf. on Civil, Structural and Environmental Engineering Computing, Funchal, Portugal, Civil-Comp Press, Stirlingshire, UK, pap. 192 (10 p.), 2009. doi:10.4203/ccp.91.192.

[34] Seitl, S., Hutař, P., Veselý, V., Keršner, Z., T-stress values during fracture in wedge splitting test geometries: a numerical study, in: A. Brandt, J. Olek and I. H. Marshall (Eds.), Proc. of Int. Symp. Brittle Matrix Composites 9, Warsaw, IFTR and Woodhead Publ., 2009, 419-428.

[35] ANSYS Users manual version 10.0, Swanson Analysis System, Inc., Houston, 2005. 